\title{
HETEROTOPIC CARDIOMYOCYTES IN THE WALL OF PULMONARY VESSELS IN EXPERIMENTAL ANIMALS
}

\author{
Rostislav Kod'ousek
}

\author{
Institute of Pathology, Medical Faculty, Palacký University, Olomouc, Czech Republic \\ e-mail: kodousek@tunw.upol.cz
}

Received: September 22, 2002

Key words: Cardiomyocytes / Pulmonary veins / Laboratory animals

Heterotopic cardiomyocytes (CMC) have been described in the wall of pulmonary veins including intraparenchymatous branches, in various species of laboratory animals. Brief note is given here of their morphology including electron microscopy and immunohistological findings. From the current literature hints concerning arrhythmogenic activity of heterotopic CMC in pulmonary vessels in the possible initiation of atrial tachyarrhythmia and fibrillation are also mentioned.

\section{INTRODUCTION}

In previous experimental studies we have repeatedly observed the heterotopic occurence of cardiomyocytes $(\mathrm{CMC})$ in the walls of pulmonary vessels in various species of laboratory animals, more especially white mice, including genetic lines of athymic nude mice $\mathrm{Nu} / \mathrm{Nu}$, and in rabbits. In these cases, however, the heterotopic occurrence of CMC in vessel walls also included their deep intraparenchymal ramification in regions far from the pulmonary hilus and the venoatrial junction. These findings were verified histologically, immunohistologically and by ultrastructural electron microscopic examination. In view of the current clinical relevance of heterotopic $\mathrm{CMC}$ in pulmonary veins as possible foci of arrhythmogenic activity leading to atrial tachyarrhythmia and fibrillation, our findings are briefly mentioned in this communication.

\section{MATERIAL AND METHODS}

The laboratory animals, that were used from several experimental projects and various breedings were as follows: 1 . Genetic line $\mathrm{Nu} / \mathrm{Nu}$ (athymic $\mathrm{T}$ - deficient nude mice) - Biophysical Institute of the Medical Faculty of Charles University in Prague (Dr. P. Poučková); 2. Experimental mice from the Biological Institute of the Medical Faculty of Palacký University in Olomouc (prof. Dr. M. Hejtmánek); 3. Imbred mice from the Institute of Biotechnology, ibidem (Doc. Dr. E. Weigl); Experimental mice from the Institute of Pathology, ibidem (prof. Dr. Z. Kolár); 5. "Abursal B-deficient nude rabbit" - Laboratory of experimental medicine, ibidem (Dr. M. Hajdúch); and 6. Experimental rabbit Biological Institute, ibidem as sub 2).
The tissues were fixed in $10 \%$ formalin for histologic studies using various routine and special staining methods (Hematoxylin and eosin stain, Phosphorwolfram hematoxylin, Masson' trichrom stain, modified Heidenhain iron hematoxylin etc.). Selected tissue blocks positive for $\mathrm{CMC}$ were examined by immunohistological methods for the expression of specific markers of muscle tissue (Desmin, Sarcomeric actin, Smooth muscle actin, Calponin); furthermore, after proper osmification the tissues were examined using an electron microscope.

\section{RESULTS AND DISCUSSION}

The occurence of cellular elements of myocardial tissue in the wall of the large pulmonary veins in man and animals was considered in the past to be a continual extension of cardiomyocytes (CMC) from the left atrial myocardium into the vessels wall in the region of the veno-atrial junction ${ }^{1}$. In recent years the histological and experimental findings of CMC (autonomous rhythmogen and/or contractile ones) in the walls of pulmonary veins have also been reported by several authors ${ }^{2,3,4}$. At present, this problem assumes particular interest in that the heterotopic CMC may be the source of arrhythmogenic activity and subsequently of atrial fibrillation ${ }^{5,6,7}$.

The findings of heterotopic CMC in pulmonary veins have been most of them described in the region reaching from the left veno-atrial junction in a distal direction to the lung hilus. From our observations, heterotopic CMC in some laboratory animals were also present in the intraparenchymatous ramification of the pulmonary vessels. This fact has permitted us to make some assumptions about their dysontogenetic origin. It was suprisingly noted, that CMC were present focally in certain areas only in the ramification of pulmonary blood 


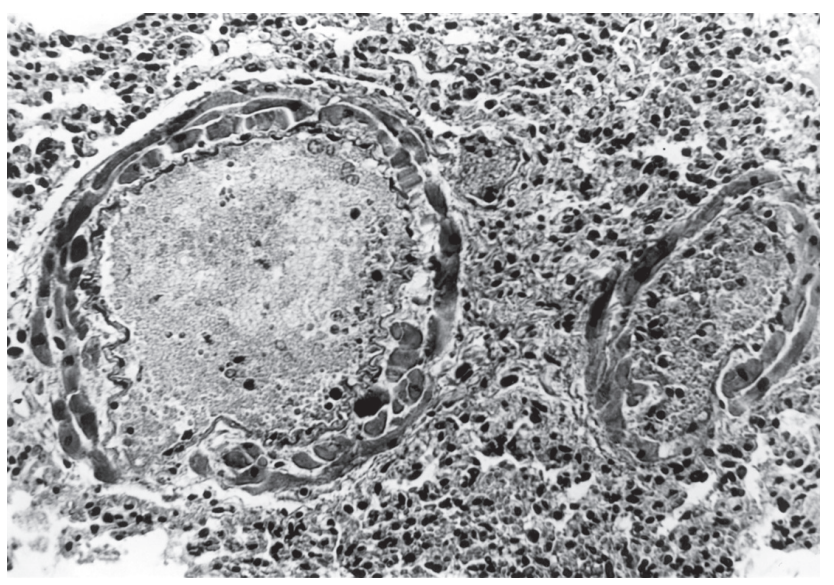

Fig. 1. Intraparenchymatous branches of pulmonary blood vessels in a white mouse, their wall consisting of longitudinal and circular layers of cardiomyocytes. E - 14283, HE stain, Mifo K-13501, Orig. magn. $90 \times /$ lin. $\times 5$.

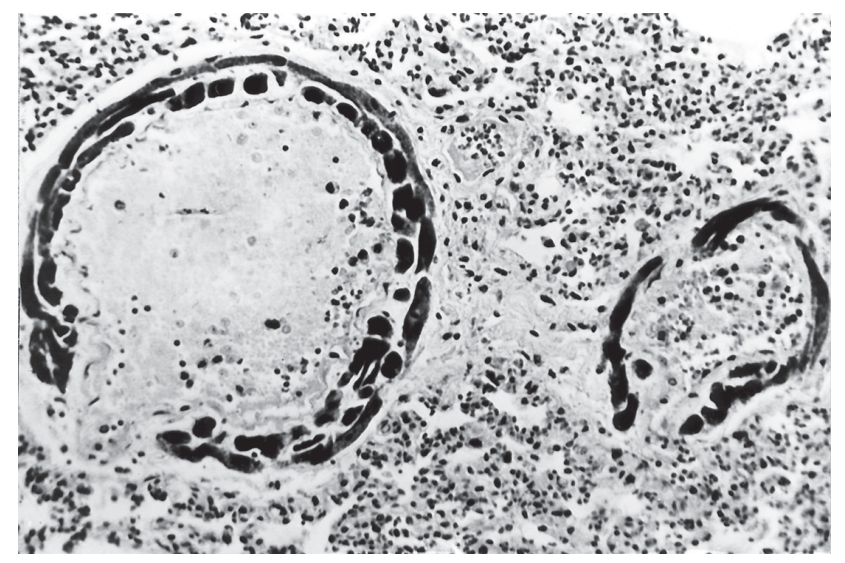

Fig. 2. In Heidenhain's method using iron hematoxylin all the cardiomyocytes in vessel walls are selectively black stained. E- 14283, Heidenhain's iron hematoxylin, Mifo LH-37725, Magn. $90 \times$.

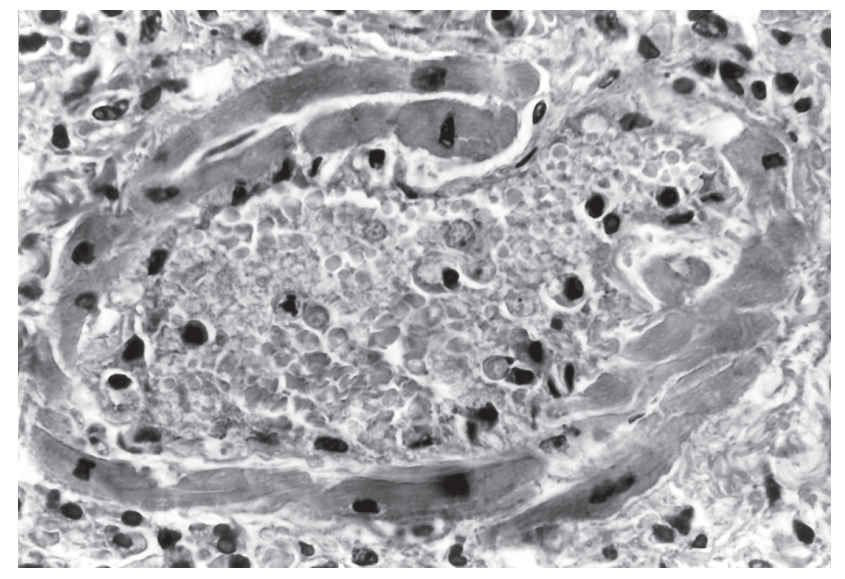

Fig. 3. Some structural pleiomorphism of individual cardiomyocytes in the wall of pulmonary vein of experimental mouse. E-14283, HE stain, Mifo K-13502, Magn. 220×.

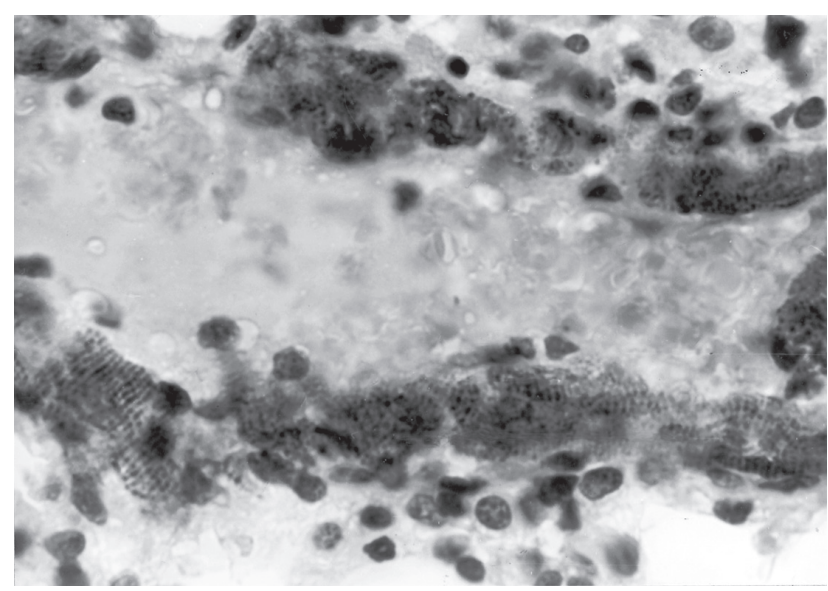

Fig. 4. Strong desmin positivity in all cardiomyocytes of the wall of a pulmonary vein in experimental mouse. E-11336/3, Immunostain for desmin, Mifo LH-37530, Magn. 300×.

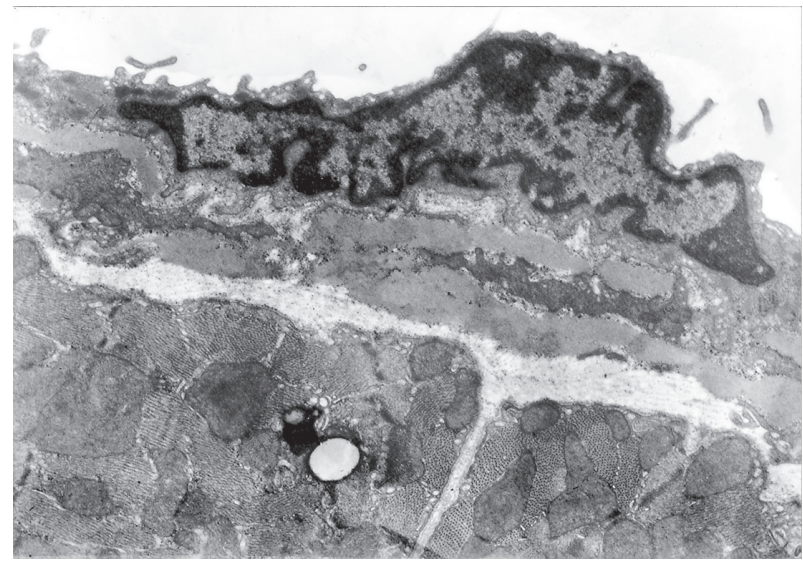

Fig. 5. Electron microscopic feature of the inner portion of a branch of pulmonary vein in experimental white mouse. Endothelial cell and longitudinal and circular layer of heart muscle cells are documented. E-14283, EM-23010, Orig. magn. 8000×.

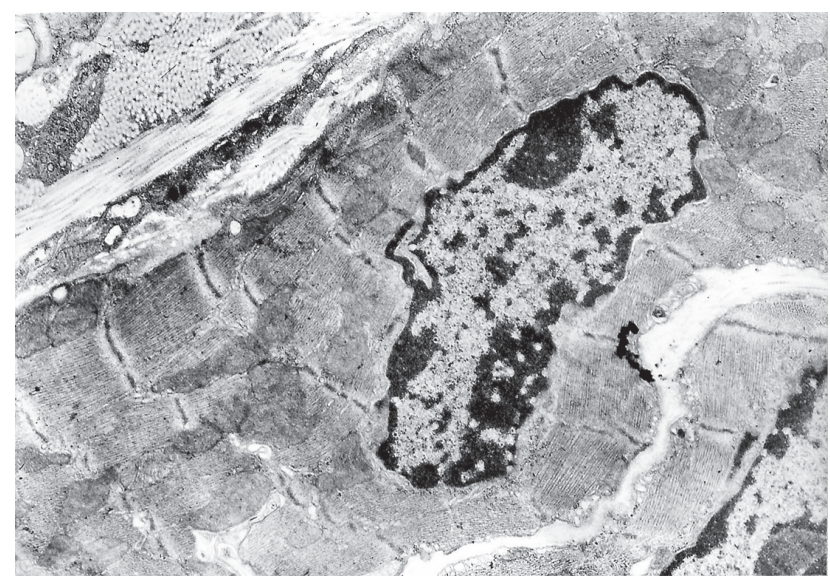

Fig. 6. Ultrastructural feature of a cardiomyocyte in the wall of a pulmonary vein in experimental mouse. Myofibrilar structures and characteristic periodicity of fibers are clearly discernible. E-14283, EM-23016, Orig.magn. 8000×. 


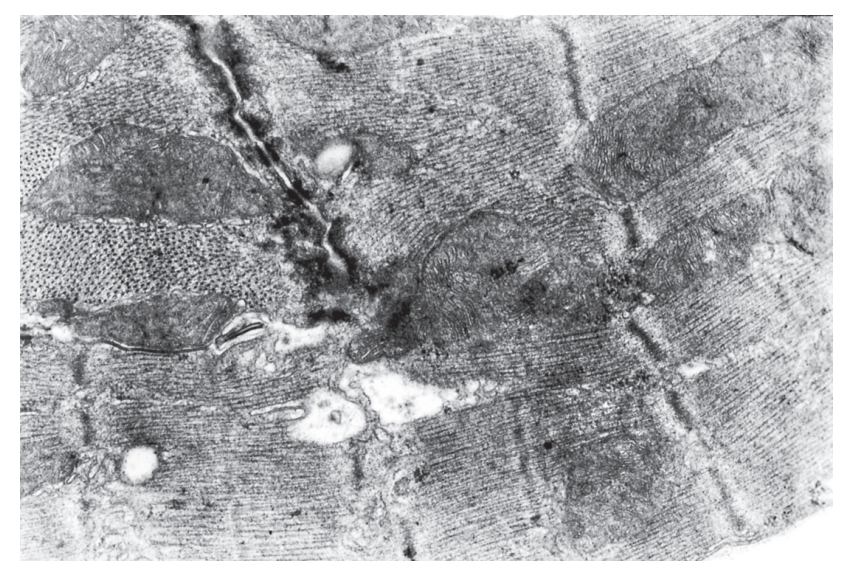

Fig. 7. Structural details of a cardiomyocyte showing numerous fibers with myofibrills, periodicity of striation and intercalar discs. Numerous mitochondria are also present. E-14283, Elmi23012, Orig. magn. $14000 \times$.

vessels. In some cases it was quite difficult to differentiate morphologically lesions of the intraparenchymatous segment of the venous and arterial wall.

Immunohistology showed marked positivity of CMC in the reactions for sarcomeric actin and desmin, whereas expression of smooth muscle actin (SMA) concerned the smooth muscle cells in vessel wall and bronchial structures. These markers (including calponin) were used previously for grading the CMC maturation in prenatal rat hearts 8 .

Electron microscopy showed normal endothelium of pulmonary vessels and typical morphology of CMC in their walls - i. e. the myofilaments, cross striation, Zbands and especially the intercalar discs, characteristic of myocardial tisuue.

The extent of CMC, which were present in the intraparenchymatous ramification of pulmonary blood vessels were not quantified or stereotopically studied. Apart from typical CMC in the wall of large pulmonary veins, some thin ("piloid") myocytes in the intima were also noticed; these probably smooth muscle elements contained some myofilaments and showed also strong coexpression of desmin (v. s. possible dual differentiation).

According to the literature, the heterotopic CMCs in the walls of pulmonary veins may represent a source of arrhythmogenic activity with the possibility of consequent atrial tachyarrhythmia or fibrillation. Chen et al. ${ }^{3}$ reported in $40 \%$ of isolated CMC in dogs a rhythmogenic ("pacemaker") activity. The heterotopic occurence of $\mathrm{CMC}$ in the walls of pulmonary veins is at present a matter of studies, oriented toward the clinical problem of atrial fibrillation.

\section{REFERENCES}

1. Stöhr P, von Möllendorf P, Goerttler K (1955) Lehrbuch der Histologie. G. Fischer Verl., Jena.

2. Cheung DW (1981): Pulmonary vein as an ectopic focus in digitalis-induced arrhythmia. Nature 294, 582-4.

3. Chen Yi-Jen, Chen Shih-Ann, Chen Yao Chang, et al. (2001): Effects of rapid atrial pacing on the arrhythmogenic activity of single cardiomyocytes from pulmonary veins. Implication in initiation of atrial fibrillation. Circulation 104, 2849-54.

4. Saito T, Waki K, Becker AE (2000) Left atrial myocardial extension onto pulmonary veins in humans: anatomic observations relevant for atrial arrhythmias. J. Cardiovasc. Electrophysiol. 11, 888-894.

5. Haissaguerre M, Jais P, Shah DC, et al. (1998) Spontaneous initiation of atrial fibrillation by ectopic beats originating in the pulmonary veins. N. Engl. J. Med. 339, 659-666.

6. Chen SA, Hsieh MH, Tai CT, et al. (1999) Initiation of atrial fibrillation by ectopic beats originating from pulmonary veins: electrophysiological characteristics, pharmacologic responses, and effects of radiofrequency ablation. Circulation 100, $1879-1886$.

7. Kautzner J, Kholová I, Dědič K (2001): Variability in myocardial extensions over the pulmonary veins: implications for catheter ablation of atrial fibrillation initiated from pulmonary venous foci. In press.

8. Markman MW, Wagenaar GT, Blommaart PJ, et al. (1977) Expression of the smooth-muscle proteins alpha-smooth-muscle actin and calponin, and of the intermediate filament protein desmin are parameters of cardiomyocyte maturation in prenatal rat heart. Anat. Rec. 249/4, 495-505. 